\title{
Development and Validation of a Sub-National, Satellite-Based Land-Use Regression Model for Annual Nitrogen Dioxide Concentrations in North-Western China
}

\author{
Igor Popovic ${ }^{1,2, *}$, Ricardo J. Soares Magalhães ${ }^{2,3}$, Shukun Yang ${ }^{4}$, Yurong Yang ${ }^{5}$, Erjia Ge ${ }^{6}$ (D), Boyi Yang ${ }^{7}$, \\ Guanghui Dong ${ }^{8}(\mathbb{D})$, Xiaolin Wei ${ }^{6}{ }^{\mathbb{D}}$, Guy B. Marks ${ }^{9,10,11}$ and Luke D. Knibbs ${ }^{11,12}$
}

1 Faculty of Medicine, School of Public Health, University of Queensland, Herston 4006, Australia

2 UQ Spatial Epidemiology Laboratory, School of Veterinary Science, University of Queensland, Gatton 4343, Australia; r.magalhaes@uq.edu.au

3 Children's Health and Environment Program, UQ Children's Health Research Center, The University of Queensland, South Brisbane 4101, Australia

4 Department of Radiology, The Second Affiliated Hospital of Ningxia Medical University, The First People's Hospital in Yinchuan, Yinchuan 750004, China; shukunyang@163.com

5 Department of Pathogenic Biology \& Medical Immunology, School of Basic Medical Science, Ningxia Medical University, Yinchuan 750004, China; yangyurong@hotmail.com

check for updates

Citation: Popovic, I.;

Magalhães, R.J.S.; Yang, S.; Yang, Y.; Ge, E.; Yang, B.; Dong, G.; Wei, X.; Marks, G.B.; Knibbs, L.D Development and Validation of a Sub-National, Satellite-Based Land-Use Regression Model for Annual Nitrogen Dioxide Concentrations in North-Western China. Int. J. Environ. Res. Public Health 2021, 18, 12887. https:/ / doi.org/10.3390/ijerph182412887

Academic Editors: Marloes Eeftens and Paul B. Tchounwou

Received: 12 October 2021

Accepted: 3 December 2021

Published: 7 December 2021

Publisher's Note: MDPI stays neutral with regard to jurisdictional claims in published maps and institutional affiliations.

Copyright: (C) 2021 by the authors Licensee MDPI, Basel, Switzerland. This article is an open access article distributed under the terms and conditions of the Creative Commons Attribution (CC BY) license (https:/ / creativecommons.org/licenses/by/ $4.0 /)$.
6 Dalla Lana School of Public Health, University of Toronto, Toronto, ON M5S 1A1, Canada; erjia.ge@utoronto.ca (E.G.); xiaolin.wei@utoronto.ca (X.W.)

7 Guangdong Provincial Engineering Technology Research Center of Environmental Pollution and Health Risk Assessment, Department of Occupational and Environmental Health, School of Public Health, Sun Yat-sen University, Guangzhou 510085, China; yangby23@mail.sysu.edu.cn

8 Guangzhou Key Laboratory of Environmental Pollution and Health Risk Assessment, Department of Preventive Medicine, School of Public Health, Sun Yat-sen University, Guangzhou 510085, China; donggh5@mail.sysu.edu.cn

9 South Western Sydney Clinical School, University of New South Wales, Liverpool 2170, Australia; g.marks@unsw.edu.au

10 Woolcock Institute of Medical Research, Glebe 2037, Australia

11 Centre for Air Pollution, Energy and Health Research, Glebe 2037, Australia; luke.knibbs@sydney.edu.au

12 Faculty of Medicine and Health, School of Public Health, The University of Sydney, Camperdown 2006, Australia

* Correspondence: i.popovic@uq.edu.au

\begin{abstract}
Existing national- or continental-scale models of nitrogen dioxide $\left(\mathrm{NO}_{2}\right)$ exposure have a limited capacity to capture subnational spatial variability in sparsely-populated parts of the world where $\mathrm{NO}_{2}$ sources may vary. To test and validate our approach, we developed a land-use regression (LUR) model for $\mathrm{NO}_{2}$ for Ningxia Hui Autonomous Region (NHAR) and surrounding areas, a small rural province in north-western China. Using hourly $\mathrm{NO}_{2}$ measurements from 105 continuous monitoring sites in 2019, a supervised, forward addition, linear regression approach was adopted to develop the model, assessing 270 potential predictor variables, including tropospheric $\mathrm{NO}_{2}$, optically measured by the Aura satellite. The final model was cross-validated (5-fold cross validation), and its historical performance (back to 2014) assessed using 41 independent monitoring sites not used for model development. The final model captured 63\% of annual $\mathrm{NO}_{2}$ in NHAR (RMSE: $6 \mathrm{ppb}$ ( $21 \%$ of the mean of all monitoring sites)) and contiguous parts of Inner Mongolia, Gansu, and Shaanxi Provinces. Cross-validation and independent evaluation against historical data yielded adjusted $\mathrm{R}^{2}$ values that were $1 \%$ and $10 \%$ lower than the model development values, respectively, with comparable RMSE. The findings suggest that a parsimonious, satellite-based LUR model is robust and can be used to capture spatial contrasts in annual $\mathrm{NO}_{2}$ in the relatively sparsely-populated areas in NHAR and neighbouring provinces.
\end{abstract}

Keywords: air pollution modelling; nitrogen dioxide; satellite-based model; land-use regression; exposure assessment; China 


\section{Introduction}

Air pollution is implicated in an estimated 4 million premature deaths globally each year [1]. The increasing global health burden attributable to air pollution is driven by population and economic growth, reflecting rapid industrialisation and urbanization, particularly in developing nations [2,3]. The highest burden of disease due to outdoor air pollutants as quantified by Disability Adjusted Life Years (DALYs) or years lost due to ill-health has consistently been recorded in Asia and Africa (2029-2751 age-standardised DALYs per 100,000 population) [4,5]. Similarly, global death rates (age-standardised) attributable to ambient air pollution vary by a factor of 10 between high-income countries (8 per 100,000 population) and low-to-middle-income countries (LMICs, 85 per 100,000 population) [1]. These severe health inequalities highlight the need for valid estimates of air pollution exposure in LMICs.

Of the major outdoor air pollutants, nitrogen dioxide $\left(\mathrm{NO}_{2}\right)$ is one of the key indicators of anthropogenic sources, such as traffic and industrial emissions [6,7]. $\mathrm{NO}_{2}$ is also an important precursor of other important air pollutants, such as ground-level ozone. However, the spatially heterogenous nature and diverse range of $\mathrm{NO}_{2}$ sources presents several challenges for modelling [8,9]. For instance, $\mathrm{NO}_{2}$ levels have been shown to decay rapidly within $\sim 150$ to $200 \mathrm{~m}$ of major roads [6,9]. Industrial activities such as combustion of fossil fuels in power stations can affect $\mathrm{NO}_{2}$ concentrations more subtly but over greater distances [10]. Generally, in urban settings, $\mathrm{NO}_{2}$ sources include coal combustion and vehicle emissions, whilst in less populated areas, contributors to $\mathrm{NO}_{2}$ levels are more likely to be regional-scale industrial emissions [11,12].

The rural and urban contrast in terms of $\mathrm{NO}_{2}$ sources is particularly apparent in China. At the start of this century, environmental policies in growing urban centres, such as Beijing and Shanghai, have led to a transition from coal to cleaner energy sources. There have also been restrictions on high-emitting vehicles [12,13]. In rural areas, however, coal is still widely used for power generation and at household level for cooking and heating. In farming areas, the use of agricultural fertilisers, machinery, and equipment can also affect $\mathrm{NO}_{2}$ concentrations [14]. As a result, $\mathrm{NO}_{2}$ exposure assessment requires consideration of both local and regional sources of the pollutant. This is particularly relevant to China, which has distinctively different sources of $\mathrm{NO}_{2}$ in large cities compared with sparsely populated rural areas in the north-west of the country [12,14].

Land-use regression (LUR) is an approach to $\mathrm{NO}_{2}$ exposure assessment modelling that has been used since the mid 1990s. More recently, however, LUR models have sought to combine satellite observations and ground level measurements with known predictors of $\mathrm{NO}_{2}$ pollution $[15,16]$. An LUR model offers improved spatial coverage and discrimination compared with what is achievable with fixed monitoring stations alone, as it can be applied to estimate air pollution exposure even in non-measured locations at an intra-urban or local scale $[17,18]$. There has been increased research interest in satellite-based LUR modelling of $\mathrm{NO}_{2}$, where tropospheric $\mathrm{NO}_{2}$ and other remotely sensed variables are used as a spatiallyvarying predictor of measured ground-level concentrations. However, existing literature is limited to global, continental models or large urban centres [7,15,16,18-20].

Current LUR models in China have potential limitations regarding their coarse spatial resolution $(>10 \mathrm{~km})$ and temporal span, which may limit validity of estimates of fine-scale intra-urban $\mathrm{NO}_{2}$ concentrations [21-23]. Additionally, the relatively limited number of monitoring sites (sample size) included in model development in previous sub-national models for China may limit the validity of their $\mathrm{NO}_{2}$ predictions [21,23-26]. The use of less spatially refined $\left(13 \times 24 \mathrm{~km}^{2}\right.$ at nadir) $\mathrm{NO}_{2}$ satellite measurements and other geographically varying predictors is also a limiting feature in current $\mathrm{NO}_{2}$ models in the country [21,23-27]. Whilst spatially refined and cross-validated global and national LUR models exist for China, their validity and generalisability to sparsely populated areas is unknown, as is the question of whether models with smaller spatial extent (e.g., sub-national) are valid in those areas $[7,28]$. 
As existing air pollution models have focused on understanding the spatial variability of $\mathrm{NO}_{2}$ in more densely inhabited local urban environments, and at a national scale, the ability of such models to assign exposure associated with rural emissions is unclear. Therefore, the objective of this study was to develop a LUR model for annual $\mathrm{NO}_{2}$ levels in Ningxia Hui Autonomous Region (NHAR) a sparsely populated province with income levels and life expectancy well below the average for China [29]. The development of the model was motivated by intention of examining the effects of $\mathrm{NO}_{2}$ and other ambient pollutants on respiratory disease outcomes in Ningxia Hui Autonomous Region. We aimed to capture important sources of $\mathrm{NO}_{2}$ exposure in a sparsely-populated region of China for which there are no comparable sub-national models. We also sought to independently validate the model against historical measurements. The findings presented in this study may inform future $\mathrm{NO}_{2}$ exposure assessment applications outside the study area by identifying important predictors of $\mathrm{NO}_{2}$ in other rural and semi-rural regions in China and beyond.

\section{Materials and Methods}

\subsection{Study Area}

Ningxia Hui Autonomous Region is the smallest provincial-level autonomous region located in Northwest China. Ningxia's territory covers an area of $66,400 \mathrm{~km}^{2}$. Administratively, NHAR is divided into five prefecture level cities (Yinchuan (2.3 million population); Shizuishan (734,400 population); Wuzhong (1.4 million population); Guyuan (1.2 million population); and Zhongwei (1.2 million population)) that are subsequently subdivided into counties/districts/county-level cities, townships, and villages [29-31]. The total population of NHAR exceeds 7.2 million people ( $>46 \%$ of the population inhabit rural areas), ranking 30th and 28th in population size and density (108 persons per $\left.\mathrm{km}^{2}\right)$, respectively, of 34 provincial level administrative divisions in China [31]. NHAR has one of the lowest GDP outputs in the country $[29,31]$.

The study area was extended to a $500 \mathrm{~km}$ radius centred on Ningxia province as a balance between increasing the number of monitoring stations without substantially changing the relationship between predictors and $\mathrm{NO}_{2}$ (i.e., the study area was assumed to be broadly similar to NHAR in $\mathrm{NO}_{2}$ sources and spatial variability). By expanding the study area beyond Ningxia, the number of available monitoring stations increased from 19 to 123 (Table S1). As a result, the study area also encompassed parts of Inner Mongolia Autonomous Region (24 million population), Gansu (25 million population), as well as Shaanxi Province (24 million population) (Figure 1). Including Shaanxi Province ensured inclusion of important regional sources and predictors of $\mathrm{NO}_{2}$ pollution, such as mining sites and coal power stations. Dominant sources of $\mathrm{NO}_{2}$ emissions are primarily located in south-eastern parts of Shaanxi, namely in Tongchuan and Xi'an as well as in Baoji. Shaanxi Province accounted for $34 \%$ of monitoring sites in the study region. Nitrogen oxide emitting iron ore processing sites located in western areas of Gansu Province (Lanzhou, Linxi, and Baiyin) were also captured in addition to petrochemical processing bases and refining industries found in north-east of Yinchuan in Ningxia Province [32].

\subsubsection{Measured $\mathrm{NO}_{2}$}

Continuous, hourly ground-level $\mathrm{NO}_{2}$ measurements were obtained for the period of 1 January to 31 December 2019 through OpenAQ [33]. This year was the first year for which hourly $\mathrm{NO}_{2}$ measurements were publicly available for a full calendar year. OpenAQ is an open-source portal that aggregates government-measured ambient air pollution data and obtains air monitoring data for China from the Chinese Environmental Monitoring Center (CEMC) as well as provincial-level Environmental Monitoring Agencies [33]. All measurements were performed using standard chemiluminescence methods, following Chinese Ambient Air Quality Standards (GB 3095-2012) and Ambient Air Quality Index (AQI) technology (HJ 633-2012). 

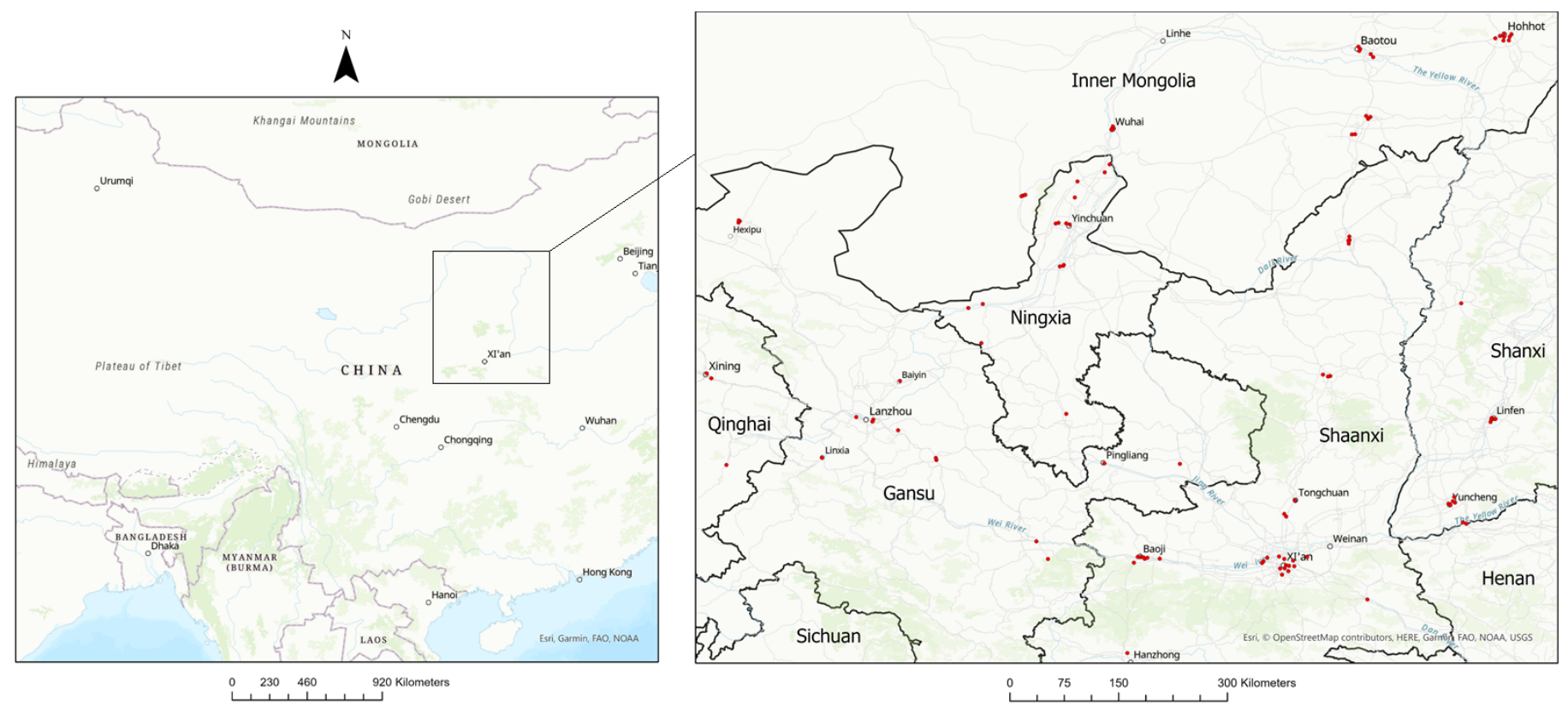

Figure 1. Location and distribution of air quality monitoring sites in study area.

Quality control and consistency checks were applied to the daily monitoring data to exclude monitoring sites with incomplete data (i.e., where measurements were not available for at least $75 \%$ of the year) and/or missing coordinates (latitude and longitude to five decimal places). A total of 123 sites were identified within a $500 \mathrm{~km}$ radius centred on NHAR. Due to the strong seasonal variation in $\mathrm{NO}_{2}$, we sought to limit the potential for bias due to missing data, and 14 sites were therefore removed ( $>25 \%$ missing daily monitoring data in the year) [34]. Annual averages for 2019 were calculated for the remaining 109 sites.

\subsubsection{Variables}

Satellite and non-satellite-based predictors of $\mathrm{NO}_{2}$, were extracted from various data sources (Table S2) and are summarised in Table 1. Selection of predictors that could best capture the spatial variability of $\mathrm{NO}_{2}$ was informed by previous global, continental, and national LUR models $[7,15,17,19,28]$. Predictors were calculated as averages within an area defined by a circle of a specified radius around the monitoring site location ("buffers" with 22 radii ranging from $100 \mathrm{~m}$ to $10 \mathrm{~km}$ ) or point estimates for the monitoring site.

Table 1. Predictor variables included in LUR model development *.

\begin{tabular}{|c|c|c|}
\hline Variable (Units) & Spatial Resolution & Point or Buffer Estimate \\
\hline OMI (Ozone Monitoring Instrument) $\mathrm{NO}_{2}$ observations (ppb) & $10 \mathrm{~km}$ & Point \\
\hline Elevation $(\mathrm{m})$ & $90 \mathrm{~m}$ & Point \\
\hline Annual mean Temperature $\left({ }^{\circ} \mathrm{C}\right)$ & $1 \mathrm{~km}$ & Point \\
\hline Annual mean Precipitation (mm) & $1 \mathrm{~km}$ & Point \\
\hline Distance to nearest major road $(\mathrm{km})$ & - & Point \\
\hline Distance to nearest coal power station $(\mathrm{km})$ & - & Point \\
\hline Vegetation cover $(\%)$ & $250 \mathrm{~m}$ & Buffer Average \\
\hline Tree cover $(\%)$ & $30 \mathrm{~m}$ & Buffer Average \\
\hline Impervious surfaces (\%) & $250 \mathrm{~m}$ & Buffer Average \\
\hline Water cover $(\%)$ & $500 \mathrm{~m}$ & Buffer Average \\
\hline Active Fires (fires $/ 1000 \mathrm{~km}^{2} /$ day) & $10 \mathrm{~km}$ & Buffer Sum \\
\hline Population density (persons $/ \mathrm{km}^{2}$ ) & $1 \mathrm{~km}$ & Buffer Average \\
\hline Major roads $(\mathrm{km})$ & - & Buffer Sum \\
\hline Minor roads $(\mathrm{km})$ & - & Buffer Sum \\
\hline Power Plant Emissions (tons of $\mathrm{CO}_{2} /$ year) & - & Buffer Sum \\
\hline Land use by type-Residential, Commercial, and Industrial (\%) & - & Buffer Average \\
\hline
\end{tabular}

* Further infor mation on predictor data sources can be found in Table S2. Buffer estimates were obtained for 22 buffer sizes, ranging from 100 m, 200 m, 300 m, 400 m, 500 m, 600 m, 700 m, 800 m, 1000 m, 1200 m, 1500 m, 1800 m, 2000 m, 2500 m, 3000 m, 3500 m, 4000 m, 5000 m, $6000 \mathrm{~m}, 7000 \mathrm{~m}, 8000 \mathrm{~m}$, and 10,000 m. 


\subsection{Model Development}

\subsubsection{Variable Selection}

A total of 270 predictors were included for initial model development for the year 2019, consisting of 264 buffer and six point variables. Predictors with $>75 \%$ missing, repeating (i.e., identical), or zero values across the monitoring sites were excluded $(n=88)$, leaving 182 for model development [16]. The predictors were centred and standardised to aid interpretation and model convergence. The expected coefficient direction of each predictor variable, based on empirical knowledge, was pre-defined (Table S2) following standard LUR modelling practice $[35,36]$. Briefly, predictors reflecting sources of $\mathrm{NO}_{2}$ such as roads, impervious surfaces, and population density, were defined to be positively associated with $\mathrm{NO}_{2}$ levels. Predictors, such as water and tree and vegetation cover, were defined as being negatively associated with $\mathrm{NO}_{2}$.

\subsubsection{Model Development}

A supervised forward stepwise linear regression approach was used. Starting with the variable most correlated with measured $\mathrm{NO}_{2}$, variables were added to the model if: (i) the regression coefficient followed the prespecified effect direction, (ii) they did not change the coefficient direction of a variable already in the model, and (iii) they increased adjusted $R^{2}$ of the model by $>1 \%[16,17,19]$. The selection process was repeated until no variables remained that satisfied the inclusion criteria. Forward stepwise linear regression and diagnostic checks was performed using olsrr package in RStudio Version 1.4.1106 [37].

\subsubsection{Model Diagnostics and Cross-Validation}

Residual plots were visually checked (Figure S1), while collinearity was assessed using variance inflation factor (VIF), with values $>3$ suggesting collinearity (Table 2). An examination of influential observations was conducted using Cook's distance $(>4 / \mathrm{n})$ and dfbeta values $(>2 / \sqrt{ } \mathrm{n})$ (Figures S2 and S3). For all diagnostic metrics, any suspect sites were sequentially removed and their effect on model composition and performance evaluated. Each of these sites was also manually investigated in Google Earth to understand the nature of the site and inform decisions about retaining or excluding the monitoring site in the final model. For example, one of the sites was situated on a mountain peak, which due to its elevated location, may have been subject to greater dispersion and wind dilution. Concentrations captured by this site $(7 \mathrm{ppb})$ were significantly lower than measurements recorded in other areas in the city of Tianshui (Gansu Province) (26-40 ppb). Moran's I was used in ArcGIS to detect spatial autocorrelation in model residuals (Figure S4).

Table 2. Summary of final LUR Model.

\begin{tabular}{|c|c|c|c|c|c|c|}
\hline Final Model Output & Predictor, Buffer (Units) & $B *$ & SE & Adj. $R^{2}$ & VIF & Contribution to Model ( $\%)$ \\
\hline $\mathrm{R}^{2}: 0.64$ & Intercept & 27.40 & 0.59 & & & \\
\hline Adj. $R^{2}: 0.63$ & (OMI) tropospheric $\mathrm{NO}_{2},(\mathrm{ppb})$ & 6.03 & 0.83 & 0.45 & 1.96 & $45 \%$ \\
\hline RMSE: $6.1 \mathrm{ppb}$ & Major roads, $5 \mathrm{~km}(\mathrm{~km})$ & 3.02 & 0.80 & 0.53 & 1.76 & $8 \%$ \\
\hline \multirow[t]{2}{*}{ \% RMSE: $21.9 \%$} & Vegetation cover, 1.8 km (\%) & -3.43 & 0.71 & 0.61 & 1.47 & $8 \%$ \\
\hline & Impervious surface, 7 km (\%) & 1.87 & 0.76 & 0.63 & 1.67 & $2 \%$ \\
\hline
\end{tabular}

* All predictors, including intercept, were significant at $<0.05$. Predictors were standardised and mean centred to allow for better interpretation of coefficients (see supplementary information). Predictors are listed in the order they were added to the model. SE, standard error; VIF, variance inflation factor; RMSE, root mean squared error (expressed as absolute in $\mathrm{ppb}$ and \% of mean $\mathrm{NO}_{2}$ for all sites); $\mathrm{ppb}$, parts per billion.

The prediction error in terms of root-mean-square error (RMSE (in ppb and also as a percentage of the mean of all monitoring sites)), mean absolute error (MAE), and $R^{2}$ of the final model was evaluated using 5 -fold cross-validation. This approach partitions the data into a training and a model building sub-set. The monitoring sites were randomly divided into five sub-sets using the caret package in RStudio Version 1.4.1106 [38]. Four data sub-sets were used to train the model and the remaining group to test the model developed. The cross-validation process was repeated between 50 and 500 times to assess stability of validation metrics (Table S3). 


\subsubsection{Independent Evaluation}

Independent evaluation of the final model was conducted using historical annual $\mathrm{NO}_{2}$ measurements for 2014 and 2015 from monitoring sites in the study area that were not available for developing the 2019 annual model $(n=41)$ (Table S4). Independent sites were identified using a previously published global scale $\mathrm{NO}_{2}$ model [19]. As with the development sites, the independent monitoring stations also used chemiluminescence to measure $\mathrm{NO}_{2}$ concentrations. The LUR model was applied to estimate the average yearly concentration for these sites (year $2014=16$; year $2015=25$ ) by matching annual time-varying predictor variables to the same period and using the 2019 regression coefficients [16]. The aim was to externally evaluate the LUR model's performance using new measurements. Specifically, we assessed the validity of applying 2019 model coefficients up to five years earlier. The same validation metrics as cross-validation were used (Table S5).

\subsubsection{Model Predictions}

Model predictions were gridded at $100 \mathrm{~m} \times 100 \mathrm{~m}$ for visualisation of spatial patterns across the study area. $\mathrm{NO}_{2}$ estimates for each grid cell centroid were calculated by multiplying the year 2019 regression coefficients to the corresponding predictor values. Historical predictions (2005-2018) were obtained by matching annual time-varying predictor variables for each year and using the 2019 regression coefficients. Population-weighted annual average $\mathrm{NO}_{2}$ levels for the 358 township-level divisions across NHAR (mean township population $2005-2018=17,602$ people; mean township area $=144 \mathrm{~km}^{2}$ ) were calculated by combining the predicted $\mathrm{NO}_{2}$ concentrations with 100 -m gridded annual population estimates $[39,40]$.

\section{Results}

\section{1. $\mathrm{NO}_{2}$ Measurements}

Mean annual $\mathrm{NO}_{2}$ concentrations at model development sites $(\mathrm{n}=105)$ ranged from 7 to $49 \mathrm{ppb}$, with an overall mean of $27.6 \mathrm{ppb}(\mathrm{SD}=10 \mathrm{ppb})$ (Figure S5).

\subsection{Model Performance}

The final LUR model is shown in Table 2. Overall, the model captured $63 \%$ of annual $\mathrm{NO}_{2}$ in NHAR (RMSE: $6 \mathrm{ppb}$ (21\% of the mean of all monitoring sites)) in 2019. The satellite-derived estimate of tropospheric $\mathrm{NO}_{2}$ accounted for the large majority of prediction performance of the model (incremental adjusted $R^{2}=45 \%$ ), while the major roads $(8 \%)$, vegetation $(8 \%)$, and impervious surfaces variables $(2 \%)$ made more modest contributions.

\subsection{Model Diagnostics and Cross-Validation}

There was no evidence of autocorrelation or other violations of linear regression assumptions in model residuals (Figures S1 and S4). VIF values did not suggest collinearity among the predictors (Table 2). Cook's distance and df-beta plots identified four sites with pronounced influence on model predictions and coefficients. Initially, each of these monitoring locations were checked for errors in input data and manually searched to assess the nature of the sites and value of retaining them in the data. Additionally, they were sequentially removed and their effect on model parameters and output evaluated (predictors selected, coefficients, significance values of included variables, and adjusted $\mathrm{R}^{2}$ ). Ultimately, all four were excluded, leaving 105 sites. Minimal changes to model output metrics (RMSE, $\mathrm{R}^{2}$, and MAE) were observed when the cross-validation process was repeated 50 (RMSE: 6.1; $\mathrm{R}^{2}: 0.63$; MAE: 4.9 ) and 500 times (RMSE: 6.1; $\mathrm{R}^{2}: 0.64 ;$ MAE: 4.9) (Table S3).

\subsection{Historical Validation}

Results of independent evaluation performed using historical $\mathrm{NO}_{2}$ measurements from monitoring sites not included $(\mathrm{n}=41)$ in model development are shown in Table S5. When the final 2019 LUR model coefficients were applied to the corresponding predictor 
values for the 16 new sites from year 2014 and additional 25 monitoring locations from 2015, a reduction of -0.09 to -0.10 in $R^{2}$ (RMSE: $4.9 \mathrm{ppb}$ ) was observed. Based on the mean bias (MB) values, our LUR model on average underpredicts historic $\mathrm{NO}_{2}$ concentrations by -0.5 to $-0.6 \mathrm{ppb}$ when exposed to new data (Figure S6).

\subsection{Model Predictions}

Model predictions for annual $\mathrm{NO}_{2}$ concentrations for Ningxia and surrounds are displayed in Figure 2. In less densely populated and more remote areas in the southwestern parts of the region, the model estimated $\mathrm{NO}_{2}$ concentrations ranging from 4 to $6 \mathrm{ppb}$.
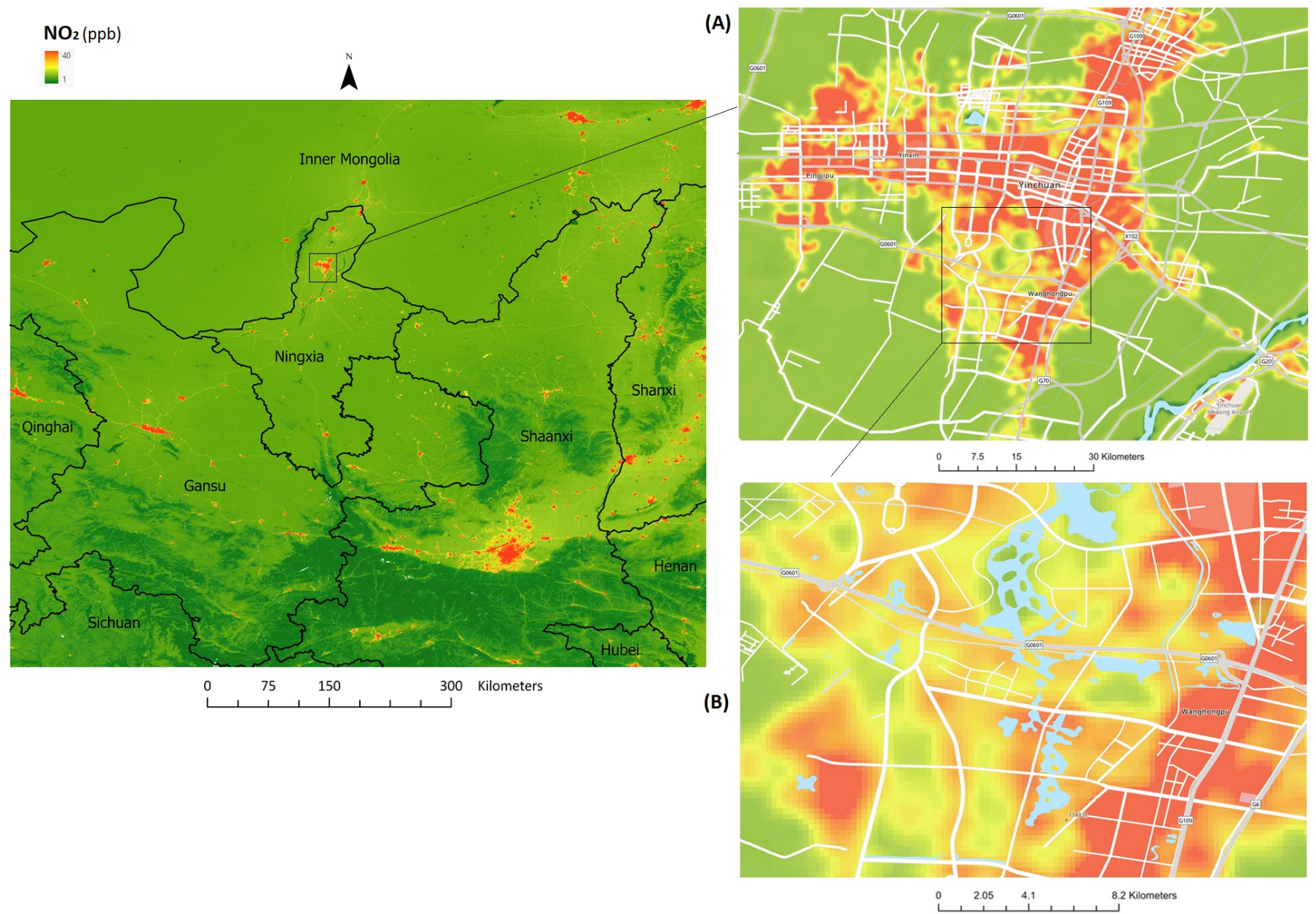

Figure 2. Mean annual $\mathrm{NO}_{2}$ model predictions for Ningxia and surroundings (2019), gridded at $100 \mathrm{~m}$ (black polygon lines represent provincial level divisions in the region). Inset (A) is of Yinchuan (2.3 million population), capital of Ningxia Province (7.2 million population). Inset (B) highlights local variability in $\mathrm{NO}_{2}$ concentrations in urban locations in Yinchuan (Estimated range: 12-38 ppb) (white polylines in insets (A,B) represent major roads).

Inset A of Figure 2 focuses on Yinchuan (capital of NHAR; population: 2.3 million). Maximum $\mathrm{NO}_{2}$ levels ( $40 \mathrm{ppb}$ ) were observed in congested areas along major roads as well as industrial and commercial districts. This pattern was consistent in other urban areas, such as Xi'an (Shaanxi Province), Lanzhou (Gansu Province), Batou (Inner Mongolia), and Hohhot (Inner Mongolia). Historic predictions (2005-2018) for 358 township-level divisions in Ningxia province are shown in Table 3. Overall, a slightly increasing trend in estimated population-weighted annual average concentrations was observed. 
Table 3. Selected percentiles of $\mathrm{NO}_{2}$ concentrations ( $\mathrm{ppb}$ ) predicted for 358 township-level divisions in Ningxia Province (2005-2018).

\begin{tabular}{cccccccc}
\hline Year & 5th & 25th & 50th & 75th & 95th & Unweighted Average & Population Weighted Average \\
\hline 2005 & 11.0 & 13.6 & 14.5 & 17.4 & 21.7 & 14.9 & 15.6 \\
2006 & 11.1 & 14.0 & 14.7 & 17.6 & 21.9 & 15.4 & 16.1 \\
2007 & 11.2 & 14.1 & 15.0 & 17.9 & 22.0 & 15.6 & 16.3 \\
2008 & 11.4 & 14.3 & 15.1 & 17.9 & 22.2 & 15.7 & 16.4 \\
2009 & 11.5 & 14.3 & 15.1 & 18.0 & 22.4 & 15.9 & 16.6 \\
2010 & 11.6 & 14.3 & 15.3 & 18.0 & 22.6 & 15.9 & 16.7 \\
2011 & 11.8 & 14.4 & 15.5 & 18.0 & 22.8 & 16.1 & 17.0 \\
2012 & 12.0 & 14.5 & 15.6 & 18.1 & 23.0 & 16.5 & 17.2 \\
2013 & 12.2 & 14.7 & 15.6 & 18.2 & 23.1 & 16.7 & 17.3 \\
2014 & 12.3 & 14.8 & 15.7 & 18.4 & 23.3 & 16.8 & 17.3 \\
2015 & 12.4 & 14.8 & 15.8 & 18.6 & 23.5 & 16.7 & 17.5 \\
2016 & 12.5 & 14.8 & 15.8 & 18.7 & 23.7 & 16.8 & 17.5 \\
2017 & 12.7 & 15.0 & 15.9 & 18.7 & 23.7 & 16.9 & 16.9 \\
2018 & 12.8 & 15.2 & 16.1 & 18.7 & 23.8 & & \\
\hline
\end{tabular}

\section{Discussion}

\subsection{Overall Findings and Model Performance}

The model captured $63 \%$ of annual $\mathrm{NO}_{2}$ in NHAR (RMSE: $6 \mathrm{ppb}$ (21\% of the mean of all monitoring sites) in 2019 (Table 2). When evaluated for prediction performance and error using independent sites from 2014 and 2015 ( $n=41$ different sites), a reduction of -0.09 to -0.10 in $R^{2}$ (RMSE: $4.9 \mathrm{ppb}$ ) was observed, which was consistent with other comparative LUR models in the literature (Table S5) $[7,20,21,23,26,27,41,42]$. As the increases in estimates noted for township-level divisions in NHAR (2005-2018) are minimal (0.2 ppb annual average increase) and within the prediction error of the model (RMSE: $6.5 \mathrm{ppb}$ ) and historical validation (2014-2015) (RMSE: $4.9 \mathrm{ppb}$ ), there was no clear evidence of an increasing trend.

\subsection{Comparison with Existing LUR Models in China}

The relatively low adjusted R2 value (63\%) of our model highlights the challenges of capturing the diverse range of mobile and static sources of a highly spatially heterogenous pollutant, such as $\mathrm{NO}_{2}$. However, the parsimonious nature of the model (four predictors) may also explain why a modest $9-10 \%$ reduction in $R^{2}$ (RMSE: $4.9 \mathrm{ppb}$ ) from training to external validation was observed, suggesting robustness when predicting at locations beyond the training sites, as is done in epidemiological studies. However, the spatial variation in $\mathrm{NO}_{2}$ concentrations explained by the LUR model is within the range of $\mathrm{R}^{2}$ values $(0.51-0.78)$ reported for previous LUR models for $\mathrm{NO}_{2}$ estimation in China $[7,20,21,23,26,27,41,42]$. Of the eight comparable annual LUR models (five city-level models, $R^{2}$ : $0.51-0.67$; two regional models, $R^{2}: 0.51-0.67$; and one national model, $R^{2}: 0.78$ ), only two included satellite observations of $\mathrm{NO}_{2}$ in model development $[7,23]$. In these models (regional model $=\mathrm{R}^{2}: 0.61$; national model $=\mathrm{R}^{2}: 0.78$ ), tropospheric $\mathrm{NO}_{2}$ measurements improved model performance by 12 to 13.5 percentage points [7,23]. In our LUR model, which has been developed for a less densely populated region, satellite measurements alone accounted for $45 \%$ of prediction of $\mathrm{NO}_{2}$ levels. We assume that the satellite observations captured important regional-scale emissions from other provinces that affected local variations in $\mathrm{NO}_{2}$ in Ningxia.

The reported differences in $\mathrm{R}^{2}$ values among annual LUR models for $\mathrm{NO}_{2}$ in China can be attributed to variation in the availability of data to inform the models. In particular, the distribution and density of monitoring sites, the availability of high-resolution data on land cover, and the use of satellite-based observations of $\mathrm{NO}_{2}$ are important factors that differ among the reported models [7,19]. Furthermore, regional and city-specific models explored smaller buffer radii around each monitoring site $(0.3$ to $3 \mathrm{~km})$ compared to our model (0.1 to $10 \mathrm{~km}$ ), which may have affected overall performance [20-23,26,41]. Improved performance was only noted in one national-level model (78\%). Xu and colleagues included ground-level measurement data from China's expanding national monitoring network consisting of more than 1382 sites [7]. The number and density of sites used likely increased their model's ability to capture fine-scale distribution patterns of $\mathrm{NO}_{2}$ [7]. 
Despite methodological differences between our LUR model and existing regional and national models, some similarities were observed. For instance, predictors of traffic-related $\mathrm{NO}_{2}$ pollution (major road length) were included in all models since vehicle emissions are a major source of the pollutant. Similarly, the inclusion of predictors of man-made or impervious surfaces were also prominent in most models, as they account for anthropogenic activities. Likewise, vegetation cover, which is negatively associated with ambient $\mathrm{NO}_{2}$ concentration, was commonly featured in existing LUR models [7,20,21,23-28,41,42]. Industrial land use was not chosen by the forward stepwise regression process in our model. Considering the remoteness of the region, there are generally fewer industrial sources of $\mathrm{NO}_{2}$ than in larger metropolitan centres and their surrounding peri-urban areas in eastern China. The study domain also had a lower density of coal power stations $\left(\sim 3\right.$ per 10,000 $\left.\mathrm{km}^{2}\right)$ compared to more populated regions in China $\left(\sim 9\right.$ per 10,000 $\left.\mathrm{km}^{2}\right)$ [32]. However, tropospheric OMI observations, which explained $45 \%$ of the spatial variability of the pollutant in the study area, likely captured industrial contributions to $\mathrm{NO}_{2}$ emissions, in addition to other sources.

\subsection{Limitations}

There was evidence of underestimation of historical $\mathrm{NO}_{2}$ concentrations by 0.5 to $0.6 \mathrm{ppb}(\sim 22 \%)$. However, underestimation of $\mathrm{NO}_{2}$ levels is more likely at higher values rather than across the range of $\mathrm{NO}_{2}$ predictions (Figure S7). LUR models are also known to be more reliable in estimating mean exposures than extreme values of $\mathrm{NO}_{2}(\mathrm{Xu}$ et al. 2019).

When evaluated using independent sites from 2014 and 2015, which is a more rigorous and realistic test of a model's performance (including historical performance up to five years prior), a drop of -0.09 to -0.10 in $\mathrm{R}^{2}$ was observed (Table S5). The RMSE of $4.9 \mathrm{ppb}$ obtained for historic validation (2014-2015) and for the 2019 model (RMSE: 6.1 ppb) suggest that the level of uncertainty or error in predictions for 2005-2019 is likely in the range of 4.9 to $6.5 \mathrm{ppb}$. This decrement in performance and in general RMSE error range is consistent with other LUR models [16]. Possible explanations include the fact that major road length and impervious surface cover were not available historically. However, as tropospheric satellite observations of $\mathrm{NO}_{2}$ (data dating back to 2004) accounted for most of the prediction performance, it provided confidence in applying our model to earlier years.

Additional sources of error may include the use of open-source ground-level monitoring data, which may have been incomplete. As the data were not obtained directly from environmental monitoring agencies in China, sites measuring important local sources of $\mathrm{NO}_{2}$ may have been missed. The locations of air quality monitors in the study area (primarily near government institutions, including schools, universities, and recreational areas) may have limited their ability to capture important spatial gradients relating to industry and airports. Model performance may also be overly optimistic, as we were unable to test our LUR model against more historic ground-level monitoring measurements (apart from 2014 and 2015) due to unavailability of data for the region.

\section{Conclusions}

The finding that $45 \%$ of $\mathrm{NO}_{2}$ was captured by satellite-derived estimates of tropospheric $\mathrm{NO}_{2}$ alone, which date back to 2004, along with the historical validation we undertook, provides support for applying 2019 coefficients to earlier years. The traditional LUR approach we used, which emphasised empirical plausibility and interpretability of coefficients, offered modestly improved predictions ( $2-4 \%$ improvement in $\mathrm{R}^{2}$ ) compared with other sub-national models for China. More importantly, the model yields valid estimates of annual $\mathrm{NO}_{2}$ in Ningxia and its immediate surrounding areas, and it will be used to estimate $\mathrm{NO}_{2}$ exposure within that spatial domain in an epidemiological study.

Supplementary Materials: The following are available online at https://www.mdpi.com/article/10 .3390/ijerph182412887/s1, NO 2 LUR Model Manuscript—Supplementary Information. Figure S1: Distribution of final LUR model residuals, Figure S2: Cook's distance plot for all sites included in final LUR model, Figure S3 (A): DF-BETA statistics plots for each predictor included in final LUR 
model. *OMINO2 represents tropospheric $\mathrm{NO}_{2}$ measurements. MR5000, VC1800 \& IS7000 stand for major roads $(5 \mathrm{~km})$, vegetation cover $(1.8 \mathrm{~km})$ and impervious surfaces $(7 \mathrm{~km})$, Figure S3 (B): DF-BETA statistics plots for each predictor included in final LUR model. * MR5000, VC1800 \& IS7000 stand for major roads $(5 \mathrm{~km})$ and vegetation cover $(1.8 \mathrm{~km})$, Figure S3 (C). DF-BETA statistics plots for each predictor included in final LUR model. ${ }^{*}$ IS7000 stands for impervious surfaces $(7 \mathrm{~km})$, Figure S4: Global Moran's I Summary for final LUR model residuals, Figure S5: Distribution of mean annual hourly average $\mathrm{NO}_{2}$ (ppb) concentrations observed at 123 monitoring sites in Ningxia and surrounding areas in 2019, Figure S6: Bland-Altman Plot showing the level of agreement between predicted $\mathrm{NO}_{2}$ concentrations (using coefficients from 2019 LUR model applied to time-varying predictors) and actual concentrations measured at historical sites (2014 \& 2015) not used in model development $(n=41)$, Figure S7: Predicted vs. observed annual mean $\mathrm{NO}_{2}(\mathrm{ppb})$ concentrations (2019) with a 1:1 regression line, Table S1: Location and number of monitoring sites by province (year 2019), Table S2: Data sources of predictor variables, Table S3: Results of k-fold cross-validation (5-fold cross-validation, Table S4: Descriptive statistics of annual mean $\mathrm{NO}_{2}(\mathrm{ppb}$ ) at model evaluation sites for years 2014 and 2015, Table S5: Independent Evaluation of LUR model at 41 Monitoring sites (Measured $\mathrm{NO}_{2}$ regressed on Predicted $\mathrm{NO}_{2}$ using LUR model).

Author Contributions: The authors confirm contribution to the manuscript as follows: Conceptualization: I.P. and L.D.K.; data collection: I.P., L.D.K., Y.Y. and S.Y.; formal analysis: I.P.; interpretation of results and validation: I.P. and L.D.K.; writing: original draft preparation: I.P.; writing: review and editing: I.P., L.D.K., G.B.M., R.J.S.M., S.Y., Y.Y., E.G., B.Y., G.D. and X.W. All authors have read and agreed to the published version of the manuscript.

Funding: Yurong Yang acknowledges funding from the National Science Foundation of China (NSFC) (NSFC Project Grant 81460311). The funding bodies had no role in the study or the decision to publish it.

Institutional Review Board Statement: Not applicable.

Informed Consent Statement: Not applicable.

Data Availability Statement: Data is contained within the article and supplementary material. The data presented and used in this study are available in $\left[\mathrm{NO}_{2}\right.$ LUR Model Manuscript—Supplementary Information].

Acknowledgments: The authors acknowledge the invaluable contribution made by the Aura Validation Data Centre, NASA Earth Observations, GeoFrabrik, SEDAC (Columbia University), and Open AQ by making landcover and land use, as well as ground monitoring and satellite observations of $\mathrm{NO}_{2}(\mathrm{OMNO} 2 \mathrm{~d}$ standard level 3 product, Version 4.0) publicly available. This has made the development of our air pollution model possible.

Conflicts of Interest: The authors have no conflict of interest to declare.

\section{References}

1. WHO. Ambient Air Pollution: A Global Assessment of Exposure and Burden of Disease; World Health Organization: Geneva, Switzerland, 2016.

2. Babatola, S.S. Global burden of diseases attributable to air pollution. J. Public Health Afr. 2018, 9, 813. [CrossRef] [PubMed]

3. Manisalidis, I.; Stavropoulou, E.; Stavropoulos, A.; Bezirtzoglou, E. Environmental and Health Impacts of Air Pollution: A Review. Front. Public Health 2020, 8, 14. [CrossRef] [PubMed]

4. GBD 2019 Risk Factors Collaborators. Global burden of 87 risk factors in 204 countries and territories, 1990-2019: A systematic analysis for the Global Burden of Disease Study 2019. Lancet 2019, 396, 1223-1249. [CrossRef]

5. Cohen, A.J.; Brauer, M.; Burnett, R.; Anderson, H.R.; Frostad, J.; Estep, K.; Balakrishnan, K.; Brunekreef, B.; Dandona, L.; Dandona, R.; et al. Estimates and 25-year trends of the global burden of disease attributable to ambient air pollution: An analysis of data from the Global Burden of Diseases Study 2015. Lancet 2017, 389, 1907-1918. [CrossRef]

6. Batterman, S.; Berrocal, V.J.; Milando, C.; Gilani, O.; Arunachalam, S.; Zhang, K.M. Enhancing Models and Measurements of Traffic-Related Air Pollutants for Health Studies Using Dispersion Modeling and Bayesian Data Fusion. Res. Rep. Health Eff. Inst. 2020, 202, 1-63.

7. Xu, H.; Bechle, M.J.; Wang, M.; Szpiro, A.A.; Vedal, S.; Bai, Y.; Marshall, J.D. National PM2.5 and NO 2 exposure models for China based on land use regression, satellite measurements, and universal kriging. Sci. Total Environ. 2019, 655, 423-433. [CrossRef] [PubMed] 
8. Kobza, J.; Geremek, M. Do the pollution related to high-traffic roads in urbanised areas pose a significant threat to the local population? Environ. Monit. Assess. 2016, 189, 33. [CrossRef]

9. Richmond-Bryant, J.; Owen, R.C.; Graham, S.; Snyder, M.; McDow, S.; Oakes, M.; Kimbrough, E.S. Estimation of on-road NO 2 concentrations, $\mathrm{NO}_{2} / \mathrm{NO}_{X}$ ratios, and related roadway gradients from near-road monitoring data. Air Qual. Atmos. Health 2017, 10, 611-625. [CrossRef] [PubMed]

10. Paraschiv, S.; Paraschiv, L.-S. Analysis of traffic and industrial source contributions to ambient air pollution with nitrogen dioxide in two urban areas in Romania. Energy Procedia 2019, 157, 1553-1560. [CrossRef]

11. Hoek, G. Methods for Assessing Long-Term Exposures to Outdoor Air Pollutants. Curr. Environ. Health Rep. 2017, 4, 450-462. [CrossRef] [PubMed]

12. Di Tommaso, M.R.; Spigarelli, F.; Barbieri, E.; Rubini, L. Challenges for the Future and the Role of Industrial Policy. In International Business and Emerging Economy Firms; Springer: Singapore, 2020; pp. 163-183.

13. Kan, H. Environment and Health in China: Challenges and Opportunities. Environ. Health Perspect. 2009, 117, A530-A531. [CrossRef]

14. Han, W.; Li, Z.; Guo, J.; Su, T.; Chen, T.; Wei, J.; Cribb, M. The Urban-Rural Heterogeneity of Air Pollution in 35 Metropolitan Regions across China. Remote Sens. 2020, 12, 2320. [CrossRef]

15. Knibbs, L.D.; Hewson, M.G.; Bechle, M.J.; Marshall, J.D.; Barnett, A. A national satellite-based land-use regression model for air pollution exposure assessment in Australia. Environ. Res. 2014, 135, 204-211. [CrossRef]

16. Knibbs, L.D.; Van Donkelaar, A.; Martin, R.V.; Bechle, M.J.; Brauer, M.; Cohen, D.D.; Cowie, C.; Dirgawati, M.; Guo, Y.; Hanigan, I.; et al. Satellite-Based Land-Use Regression for Continental-Scale Long-Term Ambient PM2.5 Exposure Assessment in Australia. Environ. Sci. Technol. 2018, 52, 12445-12455. [CrossRef]

17. Beelen, R.; Hoek, G.; Vienneau, D.; Eeftens, M.; Dimakopoulou, K.; Pedeli, X.; Tsai, M.-Y.; Künzli, N.; Schikowski, T.; Marcon, A.; et al. Development of $\mathrm{NO}_{2}$ and $\mathrm{NO}_{\mathrm{x}}$ land use regression models for estimating air pollution exposure in 36 study areas in Europe-The ESCAPE project. Atmos. Environ. 2013, 72, 10-23. [CrossRef]

18. Vienneau, D.; de Hoogh, K.; Bechle, M.J.; Beelen, R.; van Donkelaar, A.; Martin, R.V.; Millet, D.B.; Hoek, G.; Marshall, J.D. Western European Land Use Regression Incorporating Satellite- and Ground-Based Measurements of $\mathrm{NO}_{2}$ and PM10. Environ. Sci. Technol. 2013, 47, 13555-13564. [CrossRef]

19. Larkin, A.; Geddes, J.A.; Martin, R.V.; Xiao, Q.; Liu, Y.; Marshall, J.D.; Brauer, M.; Hystad, P. Global Land Use Regression Model for Nitrogen Dioxide Air Pollution. Environ. Sci. Technol. 2017, 51, 6957-6964. [CrossRef]

20. Jin, L.; Berman, J.D.; Warren, J.L.; Levy, J.I.; Thurston, G.; Zhang, Y.; Xu, X.; Wang, S.; Zhang, Y.; Bell, M.L. A land use regression model of nitrogen dioxide and fine particulate matter in a complex urban core in Lanzhou, China. Environ. Res. 2019, $177,108597$. [CrossRef] [PubMed]

21. Chen, L.; Bai, Z.; Kong, S.; Han, B.; You, Y.; Ding, X.; Du, S.; Liu, A. A land use regression for predicting $\mathrm{NO}_{2}$ and $\mathrm{PM}_{10}$ concentrations in different seasons in Tianjin region, China. J. Environ. Sci. 2010, 22, 1364-1373. [CrossRef]

22. Qin, K.; Rao, L.; Xu, J.; Bai, Y.; Zou, J.; Hao, N.; Li, S.; Yu, C. Estimating Ground Level $\mathrm{NO}_{2}$ Concentrations over Central-Eastern China Using a Satellite-Based Geographically and Temporally Weighted Regression Model. Remote Sens. 2017, 9, 950. [CrossRef]

23. Yang, X.; Zheng, Y.; Geng, G.; Liu, H.; Man, H.; Lv, Z.; He, K.; de Hoogh, K. Development of PM 2.5 and NO 2 models in a LUR framework incorporating satellite remote sensing and air quality model data in Pearl River Delta region. China. Environ. Pollut. 2017, 226, 143-153. [CrossRef]

24. Huang, L.; Zhang, C.; Bi, J. Development of land use regression models for PM2.5, $\mathrm{SO}_{2}, \mathrm{NO}_{2}$ and $\mathrm{O}_{3}$ in $\mathrm{Nanjing}$ China. Environ. Res. 2017, 158, 542-552. [CrossRef] [PubMed]

25. Li, C.; Du, S.-Y.; Bai, Z.-P.; Shao-Fei, K.; Yan, Y.; Bin, H.; Dao-Wen, H.; Li, Z.-Y. Application of land use regression for estimating concentrations of major outdoor air pollutants in Jinan, China. J. Zhejiang Univ. A 2010, 11, 857-867. [CrossRef]

26. Liu, C.; Henderson, B.H.; Wang, D.; Yang, X.; Peng, Z.-R. A land use regression application into assessing spatial variation of intraurban fine particulate matter (PM2.5) and nitrogen dioxide $\left(\mathrm{NO}_{2}\right)$ concentrations in City of Shanghai, China. Sci. Total Environ. 2016, 565, 607-615. [CrossRef]

27. Meng, X.; Chen, L.; Cai, J.; Zou, B.; Wu, C.-F.; Fu, Q.; Zhang, Y.; Liu, Y.; Kan, H. A land use regression model for estimating the $\mathrm{NO}_{2}$ concentration in shanghai, China. Environ. Res. 2015, 137, 308-315. [CrossRef] [PubMed]

28. Zhang, Z.; Wang, J.; Hart, J.E.; Laden, F.; Zhao, C.; Li, T.; Zheng, P.; Li, D.; Ye, Z.; Chen, K. National scale spatiotemporal land-use regression model for PM2.5, PM10 and $\mathrm{NO}_{2}$ concentration in China. Atmos. Environ. 2018, 192, 48-54. [CrossRef]

29. Yang, Y.R.; McManus, D.P.; Gray, D.J.; Wang, X.L.; Yang, S.K.; Ross, A.G.; Williams, G.M.; Ellis, M.K. Evaluation of the tuberculosis programme in Ningxia Hui Autonomous region, the People's Republic of China: A retrospective case study. BMC Public Health 2012, 12, 1110. [CrossRef]

30. Restrepo, A.M.C.; Yang, Y.R.; McManus, D.P.; Gray, D.J.; Barnes, T.S.; Williams, G.M.; Magalhaes, R.S.; Hamm, N.A.S.; Clements, A.C.A. Spatiotemporal patterns and environmental drivers of human echinococcoses over a twenty-year period in Ningxia Hui Autonomous Region, China. Parasites Vectors 2018, 11, 1-19. [CrossRef]

31. UN Data. City Population by Sex, City and City Type; U.N.S. Division, Ed.; United Nations: New York, NY, USA, 2021.

32. Carbon Brief. Global Coal Power Plant Emissions; Carbon Brief: London, UK, 2019.

33. OpenAQ. OpenAQ Platform; Open AQ Inc.: Washington, DC, USA, 2019. 
34. Van Der A, R.J.; Peters, D.H.M.U.; Eskes, H.; Boersma, K.F.; Van Roozendael, M.; De Smedt, I.; Kelder, H.M. Detection of the trend and seasonal variation in tropospheric $\mathrm{NO}_{2}$ over China. J. Geophys. Res. Atmos. 2006, 111, D12. [CrossRef]

35. Eeftens, M.; Beelen, R.; De Hoogh, K.; Bellander, T.; Cesaroni, G.; Cirach, M.; Declercq, C.; Dedele, A.; Dons, E.; De Nazelle, A.; et al. Development of Land Use Regression models for PM(2.5), PM(2.5) absorbance, PM(10) and PM(coarse) in 20 European study areas; results of the ESCAPE project. Environ. Sci. Technol. 2012, 46, 11195-11205. [CrossRef] [PubMed]

36. de Hoogh, K.; Gulliver, J.; van Donkelaar, A.; Martin, R.V.; Marshall, J.D.; Bechle, M.J.; Cesaroni, G.; Pradas, M.C.; Dedele, A.; Eeftens, M.; et al. Development of West-European $\mathrm{PM}(2.5)$ and $\mathrm{NO}(2)$ land use regression models incorporating satellite-derived and chemical transport modelling data. Environ. Res. 2016, 151, 1-10. [CrossRef]

37. Hebbali, A. Tools for Building OLS Regression Models; Rsquared Academy: Chennai, India, 2020.

38. Kuhn, M.W.J.; Western, S.; Williams, A.; Keefer, C.; Engelhardt, A.; Cooper, T.; Mayer, Z.; Kenkel, B.; Benesty, M.; Lescarbeau, R. Caret Package'-Misc functions for training and plotting classification and regression models. J. Stat. Softw. 2008, 28, 5.

39. Shakor, A.; Su'ad, A.; Pahrol, M.A.; Mazeli, M.I. Effects of Population Weighting on $\mathrm{PM}_{10}$ Concentration Estimation. J. Environ. Public Health 2020, 2020, 1561823.

40. WorldPop. Global High Resolution Population Denominators Project; U.o.S. School of Geography and Environmental Science, Ed.; University of Southampton: Southampton, UK, 2020.

41. Liu, W.; Li, X.; Chen, Z.; Zeng, G.; León, T.; Liang, J.; Huang, G.; Gao, Z.; Jiao, S.; He, X.; et al. Land use regression models coupled with meteorology to model spatial and temporal variability of $\mathrm{NO}_{2}$ and PM10 in Changsha, China. Atmos. Environ. 2015, 116, 272-280. [CrossRef]

42. Liu, Z.; Guan, Q.; Luo, H.; Wang, N.; Pan, N.; Yang, L.; Xiao, S.; Lin, J. Development of land use regression model and health risk assessment for $\mathrm{NO}_{2}$ in different functional areas: A case study of Xi'an, China. Atmos. Environ. 2019, 213, 515-525. [CrossRef] 